\title{
Microbial Corrosion of API 5L X-70 Carbon Steel by ATCC 7757 and Consortium of Sulfate-Reducing Bacteria
}

\author{
Arman Abdullah, ${ }^{1,2}$ Nordin Yahaya, ${ }^{1}$ Norhazilan Md Noor, ${ }^{1}$ and Rosilawati Mohd Rasol ${ }^{1}$ \\ ${ }^{1}$ Reliability Engineering and Safety Assessment Research Group (RESA), Faculty of Civil Engineering, \\ Universiti Teknologi Malaysia (UTM), 81310 Skudai, Johor, Malaysia \\ ${ }^{2}$ Faculty of Chemical Engineering and Natural Resources, Universiti Malaysia Pahang (UMP), Lebuhraya Tun Razak, \\ 26300 Kuantan, Pahang, Malaysia
}

Correspondence should be addressed to Arman Abdullah; armanabdullah@ump.edu.my

Received 26 May 2014; Revised 8 July 2014; Accepted 8 July 2014; Published 13 August 2014

Academic Editor: Tingyue Gu

Copyright (C) 2014 Arman Abdullah et al. This is an open access article distributed under the Creative Commons Attribution License, which permits unrestricted use, distribution, and reproduction in any medium, provided the original work is properly cited.

\begin{abstract}
Various cases of accidents involving microbiology influenced corrosion (MIC) were reported by the oil and gas industry. Sulfate reducing bacteria (SRB) have always been linked to MIC mechanisms as one of the major causes of localized corrosion problems. In this study, SRB colonies were isolated from the soil in suspected areas near the natural gas transmission pipeline in Malaysia. The effects of ATCC 7757 and consortium of isolated SRB upon corrosion on API 5L X-70 carbon steel coupon were investigated using a weight loss method, an open circuit potential method (OCP), and a potentiodynamic polarization curves method in anaerobic conditions. Scanning electron microscopy (SEM) and energy dispersive X-ray spectroscopy (EDS) were then used to determine the corrosion morphology in verifying the SRB activity and corrosion products formation. Results from the study show that the corrosion rate (CR) of weight loss method for the isolated SRB is recorded as $0.2017 \mathrm{~mm} / \mathrm{yr}$ compared to $0.2530 \mathrm{~mm} / \mathrm{yr}$ for ATCC 7757. The Tafel plot recorded the corrosion rate of $0.3290 \mathrm{~mm} / \mathrm{yr}$ for Sg. Ular SRB and $0.2500 \mathrm{~mm} / \mathrm{yr}$ for Desulfovibrio vulgaris. The results showed that the consortia of isolated SRB were of comparable effects and features with the single ATCC 7757 strain.
\end{abstract}

\section{Introduction}

Deterioration of metal by corrosion processes directly or indirectly involving microorganisms has gained enormous attention recently. A few terms have been used by engineers and the scientific community to highlight this type of corrosion, such as microbiologically influenced corrosion (MIC), biodeterioration, and biocorrosion [1]. Various accidents have been reported involving MIC in soil, fresh water, and seawater environments in almost all industries such as the oil and gas, power generation, marine, and nuclear industries [2-4]. The most highlighted accidents likely involving MIC as the culprit are the Carlsbad, New Mexico, natural gas pipeline explosion [5] and the 2006 Alaska pipeline leak [6]. Consequently, these devastated accidents have caused turmoil in the global oil market [6]. According to the investigation, sulfate-reducing bacteria (SRB) were the prime suspect for the accident in Alaska, proving how severe the corrosion can progress under microbial activity influence. There are many types of bacteria that can lead to corrosion initiation or the increase of corrosion rate such as SRB, acid producing bacteria (APB), and nitrate reducing bacteria (NRB) [7]. SRB is regarded as one of the most troublesome groups of bacteria influencing the MIC mechanism. SRB is usually attributed to the chemical corrosiveness of $\mathrm{H}_{2} \mathrm{~S}$, facilitated abiotic $\mathrm{H}^{+}$reduction at deposited $\mathrm{FeS}$, and biological consumption of chemically formed ("cathodic") $\mathrm{H}_{2}$. However, recent studies by Venzlaff et al. [8] and Enning et al. [9] have shown that corrosive SRB indicated direct consumption of iron-derived electrons rather than $\mathrm{H}_{2}$ as a crucial mechanism.

Bacteria need four elements to grow, namely, a carbon source, water, an electron donor, and an electron acceptor [10]. A recent theory put forward to explain the MIC mechanism is by $\mathrm{Gu}$ et al., namely, Biocatalytic Cathodic Sulfate Reduction (BCSR) [11]. Xu and Gu found that SRB starved of organic carbon are more aggressive in terms of corrosion 
of carbon steel compared to well-fed SRB $[12,13]$. Under poor nutritional conditions, SRB cell can possibly scavenge organic carbons from dead cells [14] and also maintain their energy by turning to iron $(\mathrm{Fe})$ as an electron donor due to a similar reduction potential value of lactate $\left(\mathrm{Fe}^{2+}:-447 \mathrm{mV}\right.$ and lactate: $-430 \mathrm{mV}$ ). Xu et al. [15] explained their BCSR theories by showing the combined redox reaction to have a positive potential of $+230 \mathrm{mV}$. This positive value of redox potential means the reaction is thermodynamically favorable. Consider

$$
\begin{array}{r}
\text { Anodic: } 4 \mathrm{Fe} \longrightarrow 4 \mathrm{Fe}^{2+}+8 \mathrm{e}^{-} \text {(Iron dissolution) } \\
E^{\mathrm{o}^{\prime}}=-447 \mathrm{mV}
\end{array}
$$

$$
\begin{aligned}
& \text { Cathodic: } \mathrm{SO}_{4}{ }^{2-}+9 \mathrm{H}^{+}+8 \mathrm{e}^{-} \longrightarrow \mathrm{HS}^{-}+4 \mathrm{H}_{2} \mathrm{O} \text { (BCSR) } \\
& E^{0 \prime}=-217 \mathrm{mV}
\end{aligned}
$$

Petroleum products and natural gas are commonly transported by buried pipelines under the soil for mechanical protection from third-party damage to provide thermal insulation [16]. Failure mechanisms associated with pipelines can be classified into three categories: third-party damage, material defects, and corrosion. Corrosion is recognised as one of the most dominant forms of the deterioration process and has been identified as one of the major causes of loss of containment in steel pipelines [17]. Corrosion may attack the pipelines either internally, or externally, or both. External corrosion is a major factor contributing to the deterioration of buried pipelines by weakening the pipe wall, which increases the risk of failure [18]. Even though buried pipelines are protected with coatings and cathodic protection, the pipelines are still vulnerable to various types of corrosion mechanisms [19]. MIC is one of the possible threats to buried pipelines because SRB grow well in soil sediment [20].

In order to understand the intrinsic mechanisms of MIC, it is necessary to study if the consortium of SRB bacteria species may diversify the influence on corrosion mechanism. In this paper, the corrosion behavior of ATCC 7757 SRB is compared to consortia of SRB isolated from Malaysian soil. The corrosion of carbon steel grade API 5L X-70 subject to microbial activity is monitored and measured under laboratory conditions. The findings may reveal the discrepancies between a single strain of SRB and the consortium of SRB isolated from underground in terms of bacteria metabolism and corrosion initiation. This topic is also relevant for initial recognition of bacterial species.

\section{Materials and Methods}

2.1. Sulfate-Reducing Bacteria. Two types of SRB were used in this study obtained from different sources. The first bacteria strain was sourced from the American Type Culture Collection with reference number ATCC 7757 while the second SRB strain was obtained by a simple isolation technique from soil/mud near the natural gas pipeline in
Peninsular Malaysia during pipe maintenance work. The site was selected based on the pipeline operator maintenance record (severe external corrosion from pigging record). The SRB strain was named SRB Sg. Ular for easy identification of the site location. The simple isolation was conducted by inoculating the black stain/biofilm from the pipeline under a disbonded coating in $500 \mathrm{~mL}$ nutrient-rich Baar's medium under anaerobic conditions at $37^{\circ} \mathrm{C}$. The composition of the medium consisted of sodium lactate $6.0 \mathrm{~g} / \mathrm{L}$, sodium sulfate $4.5 \mathrm{~g} / \mathrm{L}$, ammonium chloride $1.0 \mathrm{~g} / \mathrm{L}$, yeast extract $1.0 \mathrm{~g} / \mathrm{L}$, potassium phosphate $0.5 \mathrm{~g} / \mathrm{L}$, sodium citrate $0.3 \mathrm{~g} / \mathrm{L}$, calcium chloride $0.06 \mathrm{~g} / \mathrm{L}$, magnesium sulfate $0.06 \mathrm{~g} / \mathrm{L}$, and iron sulfate $0.004 \mathrm{~g} / \mathrm{L}$. The $\mathrm{pH}$ of the medium was adjusted to 7.0 before being autoclaved. The medium was sparged with oxygen-free nitrogen after being autoclaved. SRB were then detected by regrowth of the SRB with Starkey's medium as the selective growth medium. The bacteria strains obtained from the above exercise were then tested using a SRB kit, an iron reduction bacteria (IRB) kit (LAB-BART Kit, Droycon Bioconcepts Inc., Canada) and a Sani SRB test kit from SaniCheck product number 100 (Sani Check, Biosan Lab Inc., USA).

2.2. Materials. The corrosion specimens were machined from an actual segment of API 5L X-70 pipe obtained from a local gas operator. The composition of the carbon steel is as follows: $97.093 \% \mathrm{Fe}, 0.078 \% \mathrm{C}, 1.67 \% \mathrm{Mn}, 0.15 \% \mathrm{Ni}$, $0.012 \% \mathrm{P}, 0.3 \% \mathrm{Si}, 0.023 \% \mathrm{Cu}, 0.275 \% \mathrm{Cr}, 0.11 \% \mathrm{Ti}$, and $0.002 \%$ S [21]. Prior to use, the metal coupons were polished with a $\mathrm{SiC}$ grit paper graded 200,400, and 600, followed by cleaning with acetone and coated with Teflon, leaving only the flat surface exposed to the medium in an anaerobic bottle experiment. The corrosion specimen used as a working electrode was mounted in an epoxy resin with copper wire connected to an exposed flat surface approximately $1 \mathrm{~cm}^{2}$ in areas. Figure 1 shows the microstructure of the API 5L X-70 carbon steel under the microscope. The coupons consisted of ferrite and eutectoid pearlite based on the light and gray constituent color from the microstructure image.

\subsection{Method}

2.3.1. Experiment. The experiment was performed in a $125 \mathrm{~mL}$ sealed anaerobic vial and in a 1-liter electrochemical glass cell. All devices involved in this experiment were sterilized in an autoclave at $121^{\circ} \mathrm{C}$. Necessary care was taken at all times to avoid bacterial contamination and the experiments were conducted under simulated anaerobic conditions. Nitrogen for the medium was purged by using filtered oxygen-free nitrogen. The deoxygenation process was conducted for approximately 1 hour for 1 liter of medium. An open circuit potential (OCP) measurement was conducted by using a saturated calomel electrode (SCE) as the reference electrode and carbon steel as the working electrode in a standard electrochemical glass cell with the SRB medium as electrolyte. A multimeter (Kyoritsu KEW1051) was utilized to read the OCP value. Potential dynamic polarization curves 


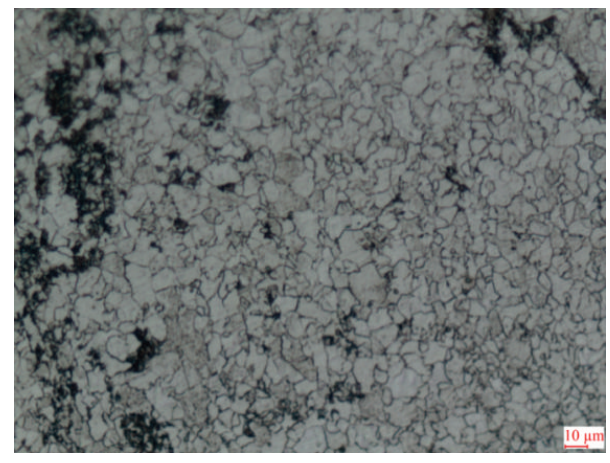

Figure 1: Microstructure of carbon steel API 5L X-70 under microscope.

were conducted in an ASTM standard cell [18] with a three-electrode system, a carbon steel coupon as a working electrode, a platinum electrode as a counterelectrode, and a saturated calomel electrode as a reference electrode. An Autolab PGSTAT 30 with General Purpose Electrochemical System (GPES) software was used to monitor the corrosion rate of the experiments.

2.3.2. Cell Counts. Planktonic SRB cell enumeration was performed to monitor bacteria growth. A sterile syringe was used to withdraw the medium from the vials before the medium was precisely diluted in distilled water. Enumeration of bacteria was counted in the Petroff-Hausser chamber under an optical microscope at 400x (three times for each sample). The SRB test kit from Bio Sani-Check product number 100 (Sani Check, Biosan Lab Inc., USA) was also used to validate the result.

2.3.3. Weight Loss and SEM Observations. The corrosion rate was calculated based on the weight loss method calculated from the following equation [17]:

$$
\mathrm{CR}=\frac{\left(m_{1}-m_{2}\right)}{S \times t},
$$

where $m_{1}$ is the mass of the specimen before corrosion (mg), $m_{2}$ is the mass of the specimen after corrosion (mg), $S$ is the total exposed area of the specimen $\left(\mathrm{cm}^{2}\right), t$ is the exposure time $(\mathrm{h})$, and CR is corrosion rate $\left(\mathrm{mg} \mathrm{cm}^{-2} \mathrm{~h}^{-1}\right)$. The biofilms on the coupon surface were observed using FESEM (model Supra 35VP). Sessile cells in the biofilm were first fixed in $4 \%$ (wt) glutaraldehyde for 4 hours and then rinsed with a series of ethanol solutions $(25 \%, 50 \%, 75 \%$, and $100 \%$ purities) to dehydrate the biofilm. They were subsequently dried by means of critical point dried (CPD) equipment using supercritical $\mathrm{CO}_{2}$ and coated with gold $(\mathrm{Au})$ prior to the biofilm being examined under FESEM. Pits observation on the coupon surface was obtained by removing the biofilm using Clarke's solution (ASTM G1-03) and washing with distilled water before being observed under FESEM.

\section{Results and Discussions}

3.1. Isolated SRB Growth. The presence of SRB was detected based on visual observation after an incubation period of 7 days in Baar's liquid medium. The medium turned to black after an incubation period of 3 to 4 days at $37^{\circ} \mathrm{C}$. After all selective mix-cultures were isolated, only 2 samples showed the presence of SRB (from the SRB kit) while no sample indicated the presence of iron reducing bacteria (from the IRB kit). Both Sg. Ular SRB samples showed rapid growth in a liquid medium. The samples also showed positive results with the Sani SRB test kit from Bio Sani-Check product number 100 (Sani Check, Biosan Lab Inc., USA). The black precipitate was indicative of iron sulfide $(\mathrm{FeS})$ as a reduction of sulfate $\left(\mathrm{SO}_{4}{ }^{2-}\right)$ to sulfide $\left(\mathrm{S}^{2}\right)$. The $\mathrm{Sg}$. Ular SRB was grown in solid agar under anaerobic conditions. Some of the surfaces of the agar have turned black, and it was a straightforward task to visualize the SRB colonies (Figure 2). A strong smell of rotten eggs was detected, indicating the production of $\mathrm{H}_{2} \mathrm{~S}$ as a result of sulphite-reducing activity by the SRB. Microorganisms were frequently found as a mixed culture in their natural habitat. Most cells survived by adhering to a surface after they were covered with a layer of polysaccharide, normally known as biofilms. In the biofilms, the microorganisms developed their own microenvironment in which their own species could resist harsh conditions [22]. The morphologies of the isolated Sg. Ular SRB revealed their features as related to the Desulfovibrio species based on the above results. Nevertheless, in this study, no genetic sequence was conducted to identify the type of Desulfovibrio sp. However, it will be undertaken as future work for this research.

Figure 3 illustrates the SRB growth curve in the $100 \mathrm{~mL}$ anaerobic vials incubated at $37^{\circ} \mathrm{C}$ for 240 hours. The SRB growth curve was attained by counting the bacteria cells under a microscope at 400x magnification and using a haemocytometer method for ATCC 7757 and Sg. Ular strain. It is noticeable that the cell number of Sg. Ular SRB started to decrease after 96 hours and the trend continues until the end of experiment. The SRB growth curve for both SRB strain results can be divided into three phases. The first was an exponential phase that started from the first hour up to 96 hours. The number of SRB increased quickly, and the SRB can potentially achieve their maximum number. In the second phase, which was from 96 hours to 168 hours, there was a steady state where the number of SRB was steadily maintained for ATCC 7757 SRB only. The dead phase was the third phase, where the SRB started to die. During this phase, the number of SRB started to decrease and the active SRB almost disappeared. The experiments were conducted in batch units and the bacteria growth decreased after a certain period due to the increase in the toxicity of sulfates $\left(\mathrm{FeS}\right.$ or $\left.\mathrm{H}_{2} \mathrm{~S}\right)$ towards SRB metabolism. Both SRB strains showed similar behaviour for 240 hours, due to the limited carbon source in the medium. This growth curve also reveals that the Sg. Ular SRB showed comparable behaviour towards a prepared medium and carbon source (lactate). 


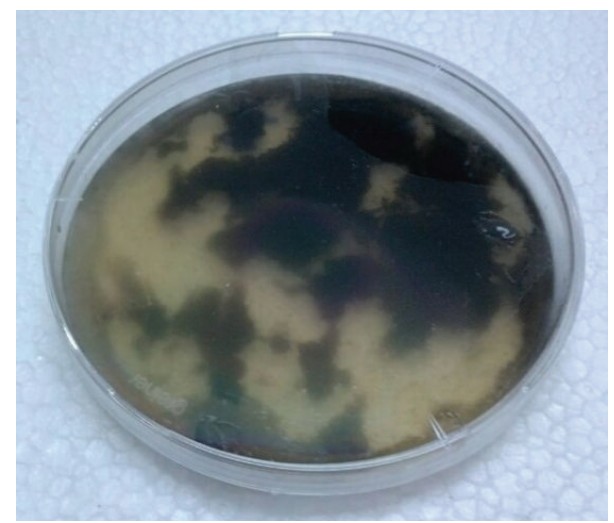

Figure 2: Colony of Sg. Ular SRB grown on agar after 7 days of incubation at $37^{\circ} \mathrm{C}$ anaerobiclly.

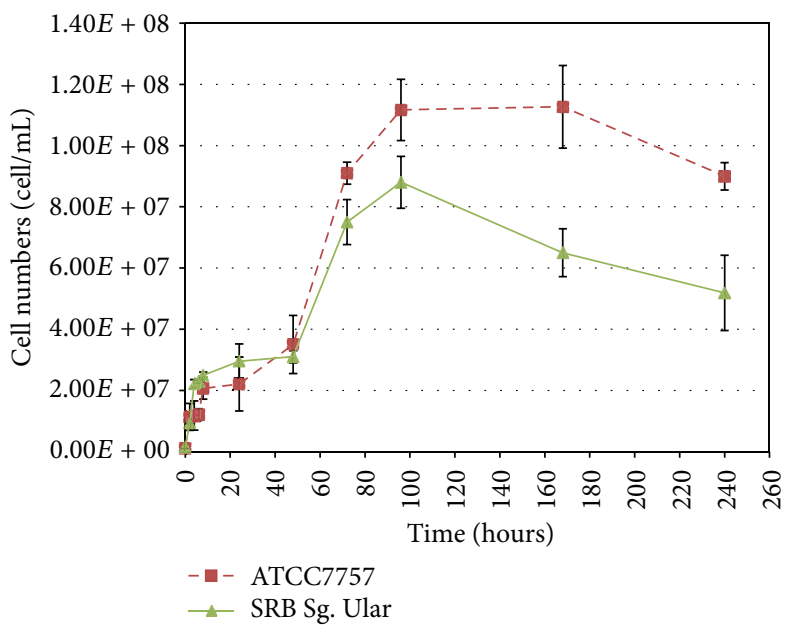

FIGURE 3: SRB growth curves for ATCC and Sg. Ular SRB strain for 240 hours at $37^{\circ} \mathrm{C}$.

3.2. Corrosion by SRB. The corrosion rates of the coupons inoculated with and without SRB were calculated as described in the weight loss procedure [21] and are shown in Table 1. Coupons exposed in ATCC 7757 bacteria show higher corrosion growth rate (CR) compared to coupons in SRB Sg. Ular after a 30-day incubation period. The values of CR for both inoculated mediums show similar trends with a higher CR observed compared to a sterile medium, proof of the influence of SRB activity in the inoculation medium. Higher CR values were observed in both inoculated vials, certainly due to $S^{2-}$ produced by SRB activity. Iron sulfide precipitated on the surface of the coupons to form a passive film. The EDS analysis detected the iron sulfide in corrosion products at the coupons' surface for both types of SRB.

The EDS revealed the presence of the corrosion products, cell spores, and EPS fibres distributed over the coupon. The EDS analyses of the corrosion products for SRB Sg. Ular and ATCC 7757 are illustrated in Figures 4(a) and 4(b), respectively. Analysis of the corrosion products on the coupon surface revealed extensively large sulphur (S) and iron $(\mathrm{Fe})$ peaks. Gold $(\mathrm{Au})$ peak was observed in Figure 4(b)

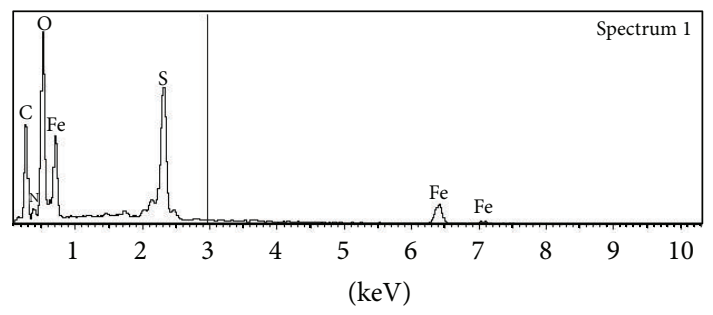

Full scale 2182 cts cursor: 2.969 ( $58 \mathrm{cts}$ )

(a)

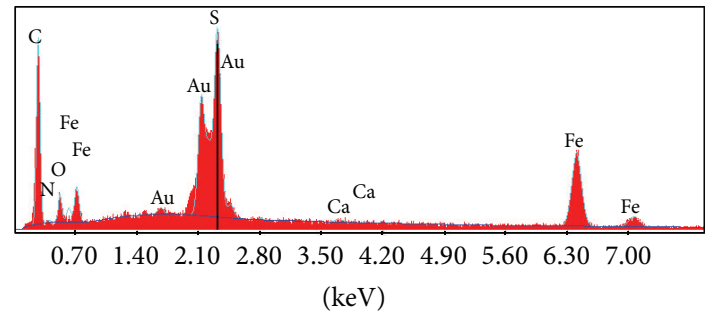

(b)

FIGURE 4: EDS analysis of biofilms for isolated SRB bacteria and ATCC inoculated at $37^{\circ} \mathrm{C}$ for 30 days.

due to the gold coated procedure conducted for ATCC 7757 sample. Oxygen peak was also revealed by the analysis, due to the exposure to oxygen during the handling process. The iron sulfide layer was formed on the metal surface by $\mathrm{Fe}^{2+}$ reacting with the hydrogen sulfide produced by SRB metabolism [23].

Figure 5 shows the results of open circuit corrosion potential, where $\left(E_{\text {corr }}\right)$ was measured again using a standard saturated calomel electrode in culture solution. The $E_{\text {corr }}$ as function of time data showed that the SRB growth substantially shifted the $E_{\text {corr }}$ to a more positive value. This shift in $E_{\text {corr }}$ value is known as ennoblement. The potential shift clearly supported the activity and growth of SRB in the culture medium by enhancing the redox quality of the medium and accelerating the iron dissolution. The SRB attached on the coupon surface to develop biofilms, and the active metabolism altered the electrochemical process in the coupon surface. The positive shift of the $E_{\text {corr }}$ as a function of time can be observed in Figure 5 for both bacteria. The ennoblement can be attributed to the bacteria colonization and biofilms formation, which resulted in organometallic catalysis and acidification of the electrode surface. The ennoblement also promoted localized corrosion such as pitting corrosion due to the transpassive dissolution of the passive film [24].

Figure 6 illustrates the polarization curves (PC) for both SRB strains inoculated in Baar's medium for incubation periods of 7 days and 21 days. From the extrapolation of the Tafel slope, corrosion current density $\left(I_{\text {corr }}\right)$, corrosion rates, and anodic $\left(\beta_{\mathrm{a}}\right)$ and cathodic $\left(\beta_{\mathrm{c}}\right)$ for SRB in Baar's medium were computed as shown in Table 2. At the initial stage of PC testing on day 7, the surface of the carbon steel coupon might not yet have been fully covered with thick biofilm and corrosion products. This could have contributed to the low CR recorded (SRB activity still did no influenced the CR). 
TABLE 1: Comparison of corrosion rate for ATCC 7757 and isolated SRB (Sg. Ular) inoculated at $37^{\circ} \mathrm{C}$ for 30 days.

\begin{tabular}{lccc}
\hline ATCC 7757 SRB's bacteria & Corrosion rate $(\mathrm{mm} / \mathrm{yr})$ & Sg. Ular SRB's bacteria & Corrosion rate $(\mathrm{mm} / \mathrm{yr})$ \\
\hline Sterile (without bacteria) & $0.0507 \pm 0.013$ & Sterile (without bacteria) & $0.0346 \pm 0.010$ \\
Inoculated & $0.2530 \pm 0.040$ & Inoculated & $0.2017 \pm 0.032$ \\
\hline
\end{tabular}

TABLE 2: Corrosion parameters obtained from Tafel plots for ATCC 7757 and Sg. Ular strain for 7 and 21 days of exposure.

\begin{tabular}{cccccc}
\hline & Days/SRB & $I_{\text {corr }}\left(\mathrm{Acm}^{-2}\right)$ & Corrosion rate $(\mathrm{mmpy})$ & $B_{\mathrm{a}}(\mathrm{V} / \mathrm{dec})$ & 0.280 \\
\hline 7 & ATCC7757 & $1.036 E-5$ & 0.1204 & 0.949 & 0.060 \\
\hline \multirow{2}{*}{21} & Sg. Ular & $9.385 E-6$ & 0.1090 & 0.029 \\
& ATCC7757 & $2.218 E-5$ & 0.2500 & 0.095 \\
\hline
\end{tabular}

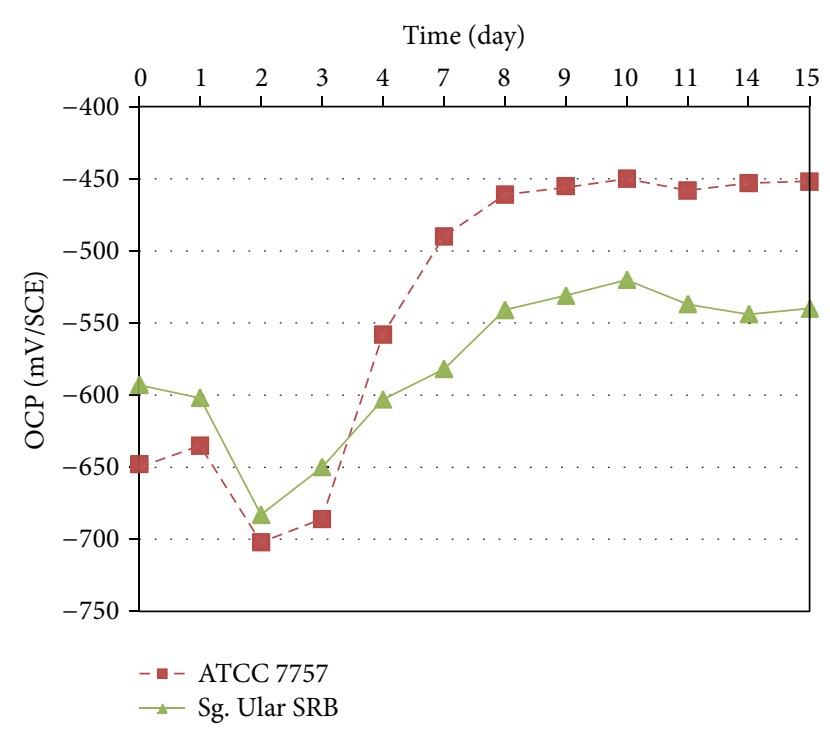

FIGURE 5: Plots of open circuit potential for carbon steel with SRB ATCC 7757 and Sg. Ular SRB.

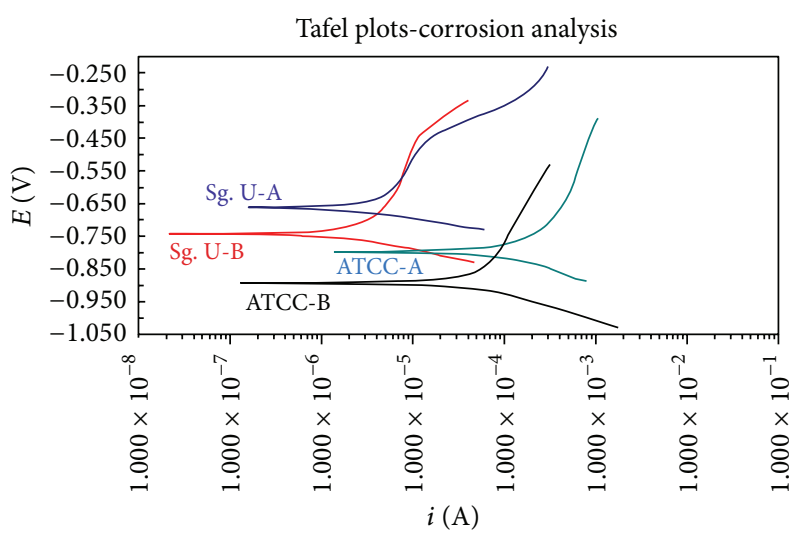

FIGURE 6: Tafel plot for ATCC 7757 and Sg. Ular. Sg. U-A is for Sg. Ular for a 21-day incubation period while Sg. U-B is for Sg. Ular for a 7-day incubation period. ATCC-A is ATCC 7757 SRB bacteria incubated for 21 days and ATCC-B is ATCC 7757 for 7 days.

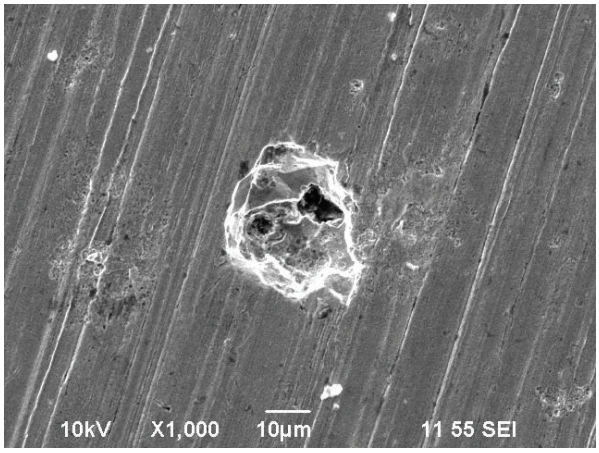

FIGURE 7: SEM micrograph of the morphology of the corrosion for Sg. Ular SRB strain after 30 days.

Higher CR was recorded on day 21 for both SRB strains. This could be attributed to the fact that the SRB activity produced hydrogen sulfide $\left(\mathrm{H}_{2} \mathrm{~S}\right)$ as a secondary metabolite, $\mathrm{H}_{2} \mathrm{~S}$, which can easily be diluted in the medium to corrode carbon steel. This is evidence to suggest that the electrochemical corrosion behaviour of carbon steel is influenced mainly by the redox quality on the biofilm, and the redox quality mainly depends on the SRB metabolism activity. The corrosion rate is barely related to SRB itself, but the biology activity of SRB is the key factor in influencing the corrosion.

3.3. Microscopic Observation. Figures 8 and 9 show the SEM images of corrosion products and biofilms developed on carbon steel coupons exposed to the Sg. Ular strain and ATCC 7757 for 30 days. Figures 8 and 9 represent the Sg. Ular SRB strain and the ATCC 7757 SRB strain, respectively. According to the images as shown in Figure 8, typical Desulfovibrio sp. SRB cells were observed with rod shapes with approximately $1.5-2.0 \mu \mathrm{m}$ sizes. After the carbon steel samples were cleaned, the surface analysis was done again to observe the morphology of the coupon. Figure 7 show some of the morphology of the carbon steel coupon exposed to the SRB Sg. Ular. Pitting corrosion was observed with the size approximated $20 \mu \mathrm{m}$. The morphology of the corrosion process is identified as localised to form pitting defect. 


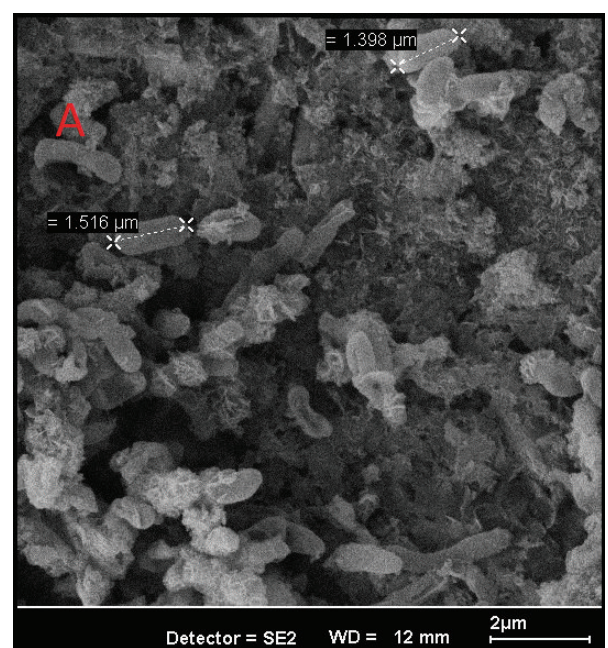

FIGURE 8: SEM images of the biofilms incubated at $37^{\circ} \mathrm{C}$ for 30 days for isolated Sg. Ular strain.

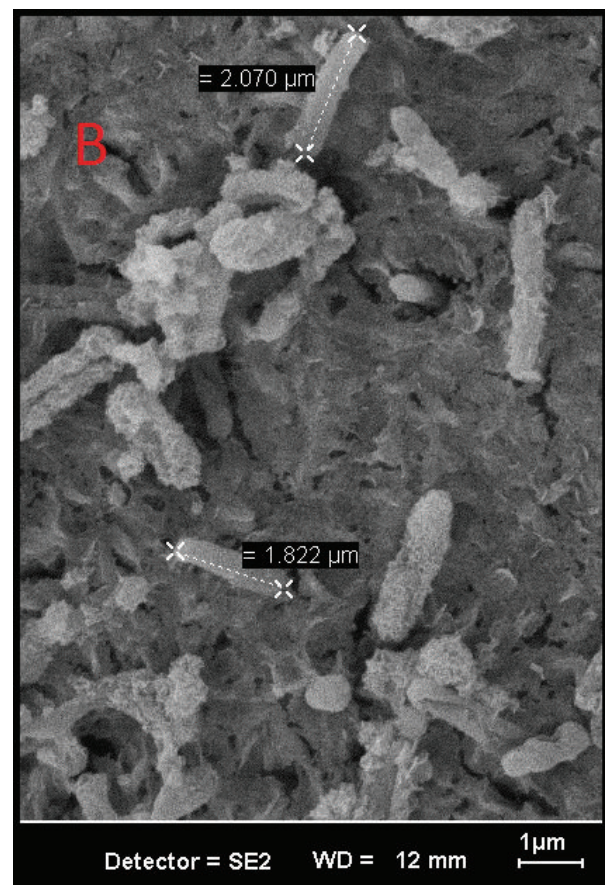

FIGURE 9: SEM images of the biofilms incubated at $37^{\circ} \mathrm{C}$ for 30 days for ATCC 7757 strain.

\section{Conclusion}

The consortium of bacteria suspected to be the SRB strain was successfully screened from the mud/soil sample taken from Sg. Ular site. Even though no genetic sequence was conducted, according to the results from SRB kits, morphology images, corrosion studies, and other methods of testing showed comparable effects and features with the ATCC 7757 strain. The growth of SRB in the limited containing culture medium showed three stages of SRB growth, namely, the exponential phase, the steady phase, and the dead phase. The ennoblement mechanism was observed from both of the Sg. Ular SRB and ATCC 7757 strains by shifting the corrosion potential to a more positive value. The corrosion rate of the carbon steel coupon was mainly affected by the SRB metabolisms activity by producing $\mathrm{H}_{2} \mathrm{~S}$ and changing the redox potential. Surface analysis showed pitting corrosion morphologies on the carbon steel coupon inoculated with isolated SRB. The EDS analysis supported the finding with high peak of $\mathrm{Fe}$ and $\mathrm{S}$ due to the presence of iron sulfide. The modelling of potential metal loss of steel pipeline in Sg. Ular area can be carried out using the laboratory ATCC 7757 strain since the growth behaviour and the impact on metal loss by this manufactured strain are comparable to Sg. Ular SRB strain, hence minimising the isolation of bacteria strain from the site.

\section{Conflict of Interests}

The authors declare that there is no conflict of interests regarding the publication of this paper.

\section{Acknowledgments}

The authors wish to acknowledge the financial support from Ministry of Education of Malaysia through RAGS Vote number RDU131414, Universiti Malaysia Pahang (UMP), and Universiti Teknologi Malaysia (UTM).

\section{References}

[1] C. G. Peng and J. K. Park, "Principal factors affecting microbiologically influenced corrosion of carbon steel," Corrosion, vol. 50, no. 9, pp. 669-675, 1994.

[2] R. Jeffrey and R. E. Melchers, "Bacteriological influence in the development of iron sulphide species in marine immersion environments," Corrosion Science, vol. 45, no. 4, pp. 693-714, 2003.

[3] R. Javaherdashti, "A review of some characteristics of MIC caused by sulfate-reducing bacteria: past, present and future," Anti-Corrosion Methods and Materials, vol. 46, no. 3, pp. 173180, 1999.

[4] R. Zuo, D. Örnek, B. C. Syrett et al., "Inhibiting mild steel corrosion from sulfate-reducing bacteria using antimicrobialproducing biofilms in Three-Mile-Island process water," Applied Microbiology and Biotechnology, vol. 64, no. 2, pp. 275-283, 2004.

[5] R. Sooknah, S. Papavinasam, and R. W. Revie, "Validation of a predictive model for microbiologically influenced corrosion," in Proceedings of the Corrosion Conference and Expo (CORROSION '08), NACE International, Houston, Tex, USA, 2008.

[6] G. A. Jacobson, "Corrosion at Prudhoe Bay-a lesson on the line," Materials Performance, vol. 46, no. 8, pp. 26-34, 2007.

[7] D. Xu, Y. Li, F. Song, and T. Gu, "Laboratory investigation of microbiologically influenced corrosion of C1018 carbon steel by nitrate reducing bacterium Bacillus licheniformis," Corrosion Science, vol. 77, pp. 385-390, 2013.

[8] H. Venzlaff, D. Enning, J. Srinivasan et al., "Accelerated cathodic reaction in microbial corrosion of iron due to direct electron uptake by sulfate-reducing bacteria," Corrosion Science, vol. 66, pp. 88-96, 2013. 
[9] D. Enning, H. Venzlaff, J. Garrelfs et al., "Marine sulfatereducing bacteria cause serious corrosion of iron under electroconductive biogenic mineral crust," Environmental Microbiology, vol. 14, no. 7, pp. 1772-1787, 2012.

[10] M. Madigan, Brock Biology of Microorganisms, Pearson Benjamin Cummings, San Francisco, Calif, USA, 12th edition, 2009.

[11] T. Gu, K. Zhao, and S. Nesic, "A practical mechanistic model for MIC based on Biocatalytic Cathodic Sulphate Reduction (BCSR) theory," in Proceeding of the CORROSION Conference, NACE International, Atlanta, Ga, USA, 2009.

[12] D. $\mathrm{Xu}$ and T. Gu, "Carbon source starvation triggered more aggressive corrosion against carbon steel by the Desulfovibrio vulgaris biofilm," International Biodeterioration \& Biodegradation, vol. 91, pp. 74-81, 2014.

[13] D. Xu and T. Gu, "Bioenergetics explains when and why more severe MIC pitting by SRB can occur," in Proceedings of the CORROSION, Houston, Tex, USA, 2011.

[14] J. W. Costerton, The Biofilm Primer, Springer, New York, NY, USA, 1st edition, 2007.

[15] D. Xu, W. Huang, G. Ruschau, J. Hornemann, J. Wen, and T. Gu, "Laboratory investigation of MIC threat due to hydrotest using untreated seawater and subsequent exposure to pipeline fluids with and without SRB spiking," Engineering Failure Analysis, vol. 28, pp. 149-159, 2013.

[16] C. Y. Cheuk, W. A. Take, M. D. Bolton, and J. R. M. S. Oliveira, "Soil restraint on buckling oil and gas pipelines buried in lumpy clay fill," Engineering Structures, vol. 29, no. 6, pp. 973-982, 2007.

[17] M. Ahammed, "Probabilistic estimation of remaining life of a pipeline in the presence of active corrosion defects," International Journal of Pressure Vessels and Piping, vol. 75, no. 4, pp. 321-329, 1998.

[18] M. Ahammed and R. E. Melchers, "Probabilistic analysis of underground pipelines subject to combined stresses and corrosion," Engineering Structures, vol. 19, no. 12, pp. 988-994, 1997.

[19] J. Xu, K. Wang, C. Sun et al., "The effects of sulfate reducing bacteria on corrosion of carbon steel Q235 under simulated disbonded coating by using electrochemical impedance spectroscopy," Corrosion Science, vol. 53, no. 4, pp. 1554-1562, 2011.

[20] D. Cetin and M. L. Aksu, "Corrosion behavior of low-alloy steel in the presence of Desulfotomaculum sp.," Corrosion Science, vol. 51, no. 8, pp. 1584-1588, 2009.

[21] N. M. Noor, N. Yahaya, A. Abdullah, M. M. Tahir, and L. K. Sing, "Microbiologically influenced corrosion of X-70 carbon steel by Desulfovibrio vulgaris," Advanced Science Letters, vol. 13, pp. 312-316, 2012.

[22] W. A. Hamilton and W. G. Characklis, "Relative activities of cells in suspension and in biofilms in Charaklis," in Structure and Function of Biofilms, W. G. Charaklis and P. A. Wilderer, Eds., John Wiley \& Sons, New York, NY, USA, 1989.

[23] F. K. Sahrani, M. Aziz, Z. Ibrahim, and A. Yahya, "Open circuit potential study of stainless steel in environment containing marine sulphate-reducing bacteria," Sains Malaysiana, vol. 37, no. 4, pp. 359-364, 2008.

[24] I. T. E. Fonseca, M. J. Feio, A. R. Lino, M. A. Reis, and V. L. Rainha, "The influence of the media on the corrosion of mild steel by Desulfovibrio desulfuricans bacteria: An electrochemical study," Electrochimica Acta, vol. 43, no. 1-2, pp. 213-222, 1998. 

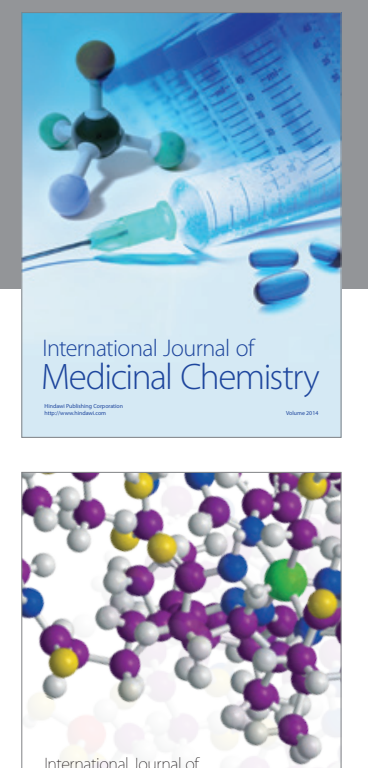

\section{Carbohydrate} Chemistry

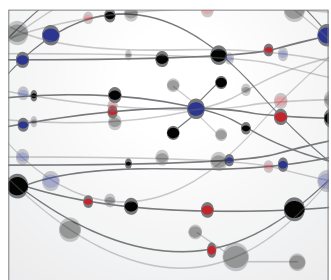

The Scientific World Journal
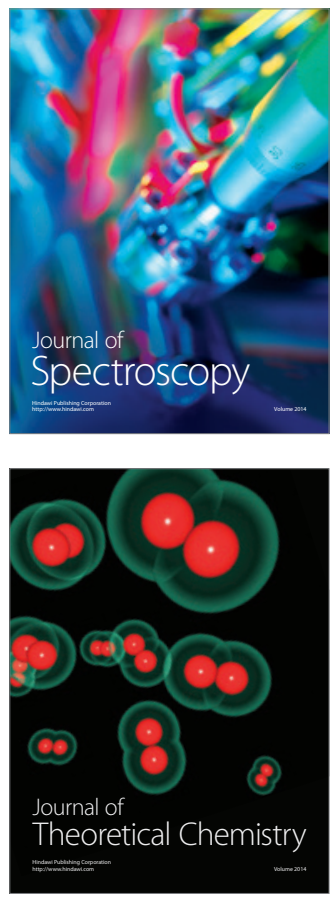
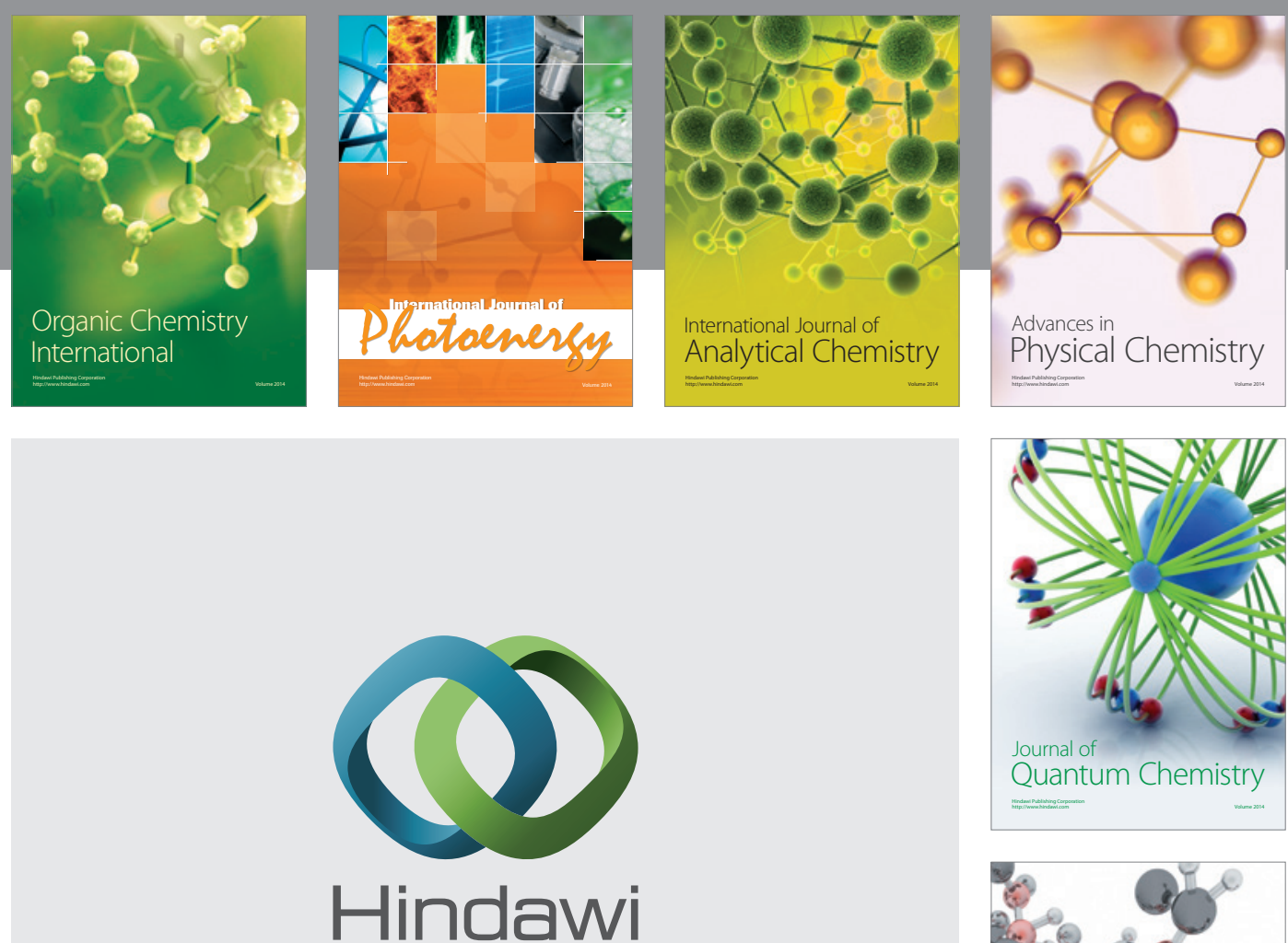

Submit your manuscripts at

http://www.hindawi.com

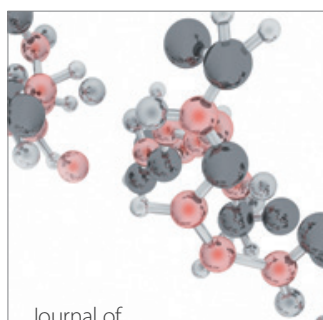

Analytical Methods

in Chemistry

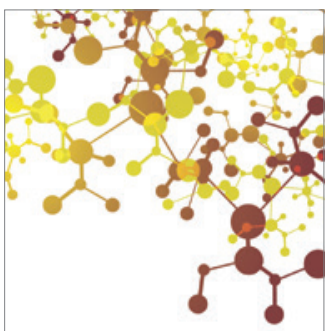

Journal of

Applied Chemistry

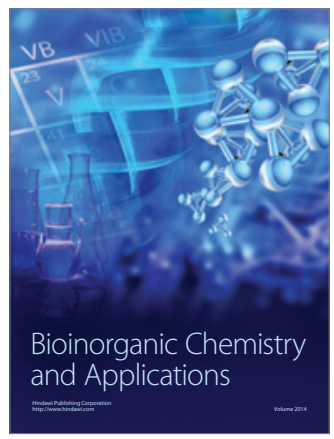

Inorganic Chemistry
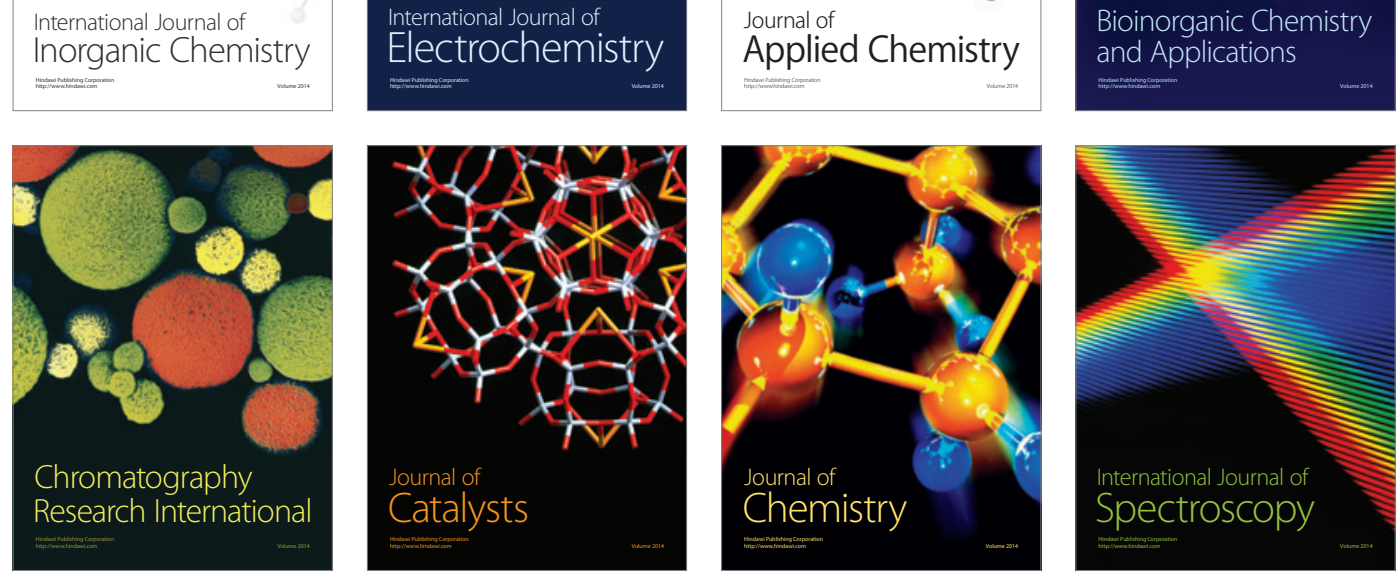